\title{
La regulación profesional es una realidad: Ley del Deporte de Andalucía
}

\section{Bartolomé J. Almagro}

En este 2016, en Andalucía (España), los profesionales de la Educación Física (EF), la actividad física y el deporte hemos vivido un importante hito: la aprobación y publicación de la Ley del Deporte de Andalucía, que en palabras del Presidente del COLEF ${ }^{1}$ de Andalucía: "marcará un antes y un después en el ejercicio de nuestras profesiones" (Serrano, 2016, p. 2). Esto es debido a que, entre otras cuestiones, la ley aborda la regulación profesional.

La Ley 5/2016, de 19 de julio, del Deporte de Andalucía incorpora un título (el séptimo), "Del ejercicio profesional del deporte" (p. 42), donde se regula el ejercicio de determinadas profesiones del deporte en la Comunidad Autónoma de Andalucía. En concreto, dicha normativa reconoce de forma expresa cuáles son tales profesiones, determinando los títulos académicos oficiales o cualificaciones profesionales necesarios para el ejercicio profesional y atribuyendo a cada profesión su correspondiente ámbito funcional. Así, se reconocen como profesiones del deporte en la Ley del Deporte de Andalucía las siguientes: profesor de Educación Física, director deportivo, entrenador deportivo (incluye al preparador físico) y monitor deportivo. Además, hay que remarcar que los servicios deportivos regulados en esta ley incluyen "cualquier manifestación de actividades deportivas orientadas a objetivos afines a la educación, rendimiento deportivo, iniciación, aprendizaje, ocio saludable, recreación u otros fines análogos" (p. 42).

La Ley de Deporte de Andalucía está compuesta por un título preliminar y nueve títulos, nueve disposiciones adicionales, siete disposiciones transitorias, una disposición derogatoria y cinco disposiciones finales. En esta editorial, por motivos de espacio, no se va a entrar a describir toda la ley, pero es necesario señalar que aborda cuestiones como: la administración y organización del deporte, establece una nueva clasificación del deporte, regula el deporte universitario, las entidades deportivas andaluzas, las instalaciones deportivas, la aplicación de políticas de fomento del deporte, la citada regulación profesional, el dopaje, la violencia e intolerancia en el deporte y los litigios deportivos.

Sin duda, la Ley del Deporte de Andalucía supone un marco legal que contribuirá a evitar el intrusismo en el sector. En este sentido, también velará por la protección de la salud y la seguridad de los consumidores y destinatarios de los servicios deportivos, así como por la calidad en la prestación de los mismos.

En suma, es una magnífica noticia la aprobación de una ley como ésta, donde la regulación de las profesiones del deporte es una realidad para los andaluces. En esta línea, otras comunidades también cuentan con su respectiva regulación profesional (Cataluña, Extremadura, La Rioja, Madrid). Sin embargo, llama la atención que a nivel nacional no se haya legislado en este sentido, lo que puede vulnerar el artículo 14 de la Constitución española, ya que el Estado parece no garantizar que todos los

\footnotetext{
${ }^{1}$ COLEF = Colegio Oficial de Licenciados en Educación Física y en Ciencias de la Actividad Física y del Deporte
} 
ciudadanos tengan una mínima igualdad $u$ homogeneidad en el ejercicio de los derechos y en el cumplimiento de los deberes, con independencia de la Comunidad Autónoma donde residan. Por éste y por otros motivos, es necesaria una intervención estatal en la regulación de las profesiones del deporte (Escudero, 2016).

Desde E-motion: Revista de Educación, Motricidad e Investigación somos optimistas y estamos convencidos que se seguirá legislando, investigando y trabajando en pro de la ciudadanía, así como que los profesionales del deporte ocuparán la posición que les corresponde en esta sociedad. Solo nos queda desear que los artículos y aportaciones de este número 6 sean de utilidad, que generen debate y que contribuyan a seguir divulgando la investigaciones o las experiencias de todo tipo de profesionales vinculados de una u otra manera a la EF, actividad física 0 el deporte.

Dr. Bartolomé J. Almagro

Profesor Ayudante Doctor de la Universidad de Huelva

Colegiado no 12214

\section{REFERENCIAS BIBLIOGRÁFICAS}

Espartero, J. (2016). Por la necesaria intervención estatal en la regulación de las profesiones del deporte. Cultura, Ciencia y Deporte, 11(31), 17-26. http://dx.doi.org/10.12800/ccd.v11i31.639

La Ley 5/2016, de 19 de julio, del Deporte de Andalucía. Boletín Oficial de la Junta de Andalucía. Sevilla, 22 de julio de 2016, núm. 140, pp. 10-65

Serrano, A. (2016). 2016: Un año cargado de retos para el COLEF de Andalucía. Habilidad Motriz, 46, 2-3. 